\title{
CASE OF EXFOLIATION
}

\section{OF THE \\ ANTERIOR ARCH OF THE ATLAS.}

BY ROBERT WADE,

SURGEON TO THE WESTMINSTER GENERAL DISPENSARY.

Received Jan. 8th.-Read Feb. 13th, 1849.

Jов Jones, aged 35, a fireman and waterman, residing at 4, Otty's Buildings, Bedfordbury, first applied to me at the Westminster Dispensary, on the 21st of October, 1845. He had a sloughy ulcer, occupying the greater part of the pharynx, and extending from the uvula backwards as far as could be seen. Near the centre of the ulcer was a nipplelike projection of pale granulations, from which pus freely oozed on pressure; and on introducing a probe at this spot, bare and rough bone was felt. The greater part of the soft palate had been destroyed by previous ulceration ; and several years before his application to me, a considerable portion of the alveolar and palatine processes of the superior maxillary bone had exfoliated, as had, also, one of the spongy bones. About twelve years ago he had a sore, of the size of a shilling, on the outside of his prepuce, for which he went into an hospital, and took three pills daily for five weeks, when he left the institution with a very sore mouth, the ulcer having then quite healed. A fortnight afterwards he returned to the hospital with an ulcerated throat, which he attributed to his having taken cold from remaining all day in wet clothes. He was ordered a course of mercurial fumigations, which were continued every night for six weeks, during the greater part of that time his mouth being very sore, and the salivation profuse. As the ulceration of his XXXII. 
mouth became much worse during the use of the fumigations, he again left the hospital, and applied to a surgeon, who desired him to discontinue the use of mercury, and to take decoction of sarsaparilla with iodide of potassium. After three or four months of this treatment, he was considered to be quite cured. He remained well for two years, when his throat again became sore, and he resumed the iodide of potassium and sarsaparilla, with the same apparent success as before. In a short time, however, after the discontinuance of his medicines, the ulceration of his throat returned, and has continued more or less to the present time, although he has taken frequent courses of sarsaparilla and iodide of potassium. The exfoliations previously noticed occurred between the third and fourth year from the commencement of his disease. It will be unnecessary to occupy the time of the Society with details of the treatment of the case after the man came under my care; it consisted principally in the administration of sarsaparilla and iodide of potassium, with chloride of soda gargles, as also the occasional application of a strong solution of nitrate of silver to the ulcer; at the same time strict injunctions were given to keep the head as free from movement as possible. The man complained of more or less constant pain in the back part of his neck, and he had occasionally attacks of very acute pain in the same part, with a rigid state of its muscles, which appeared to fix his head in a position which could not be altered without great suffering. Pressure over the upper cervical vertebræ could scarcely be borne. In these attacks, the application of leeches, followed by warm fomentations, afforded most relief; and the easiest position was obtained by the patient reclining on his right side, with the head carefully supported by a pillow. About two months after his application at the dispensary, I was hastily summoned to the man, in one of his spasmodic attacks, and found him in a state of great alarm, caused, he informed me, by his having, when raising himself in bed, felt something give way in the back of his neck, "with a loud crack like the report of a pistol," a like report having been heard also by his wife, who was with him at the time. He became very faint, thinking his neck 
was broken, and that he was dying. On looking into his mouth, some coagulated blood was seen adhering to the ulcer. Between this time and May 28, 1846, the spasmodic attacks had been less frequent as well as less severe, on which day, when looking into the pharynx, I observed a small portion of projecting bone, and with very little difficulty removed the greater part of the anterior arch of the atlas, with the entire articulating surface, from the odontoid process of the axis.

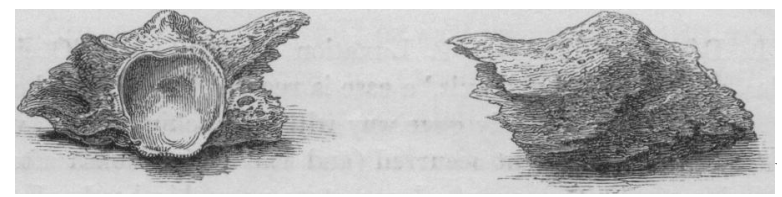

The patient was of course desired to use great caution in moving his head, and to prevent its being bent forward, was advised to wear a soldier's stiff stock for some length of time. The ulcer in the throat had for a long time a sloughy appearance; but there was no recurrence of the spasmodic affection of the muscles of the neck, after the removal of the bone, the man having been able, in the course of three months, to resume his usual occupation. The power of turning the head round is at this time nearly perfect, but it can only be bent forward to a very slight extent. The man says that whenever he attempts to bend his head forward, something appears to catch at the back of his neck, which causes pain. He informs me that the throat has occasionally healed, but has become sore again whenever he has taken cold. It has so happened, however, that although $I$ have looked at his throat at various times since the separation of the bone, there has always been a strumouslooking ulceration, covered with a tenacious yellow secretion. There is a considerable depression in the situation of the exfoliated bone.

I have ventured to bring this case before the MedicoChirurgical Society, with the hope that it may be deemed of sufficient interest to be recorded in its Transactions. I 
am not, indeed, aware of there being any similar case on record. Although, from the perfect exfoliation that had occurred, there was good reason to suppose the remaining portion of the atlas to be sound, yet of the result of the case $I$ long entertained considerable fears, as it appeared to me very doubtful whether the transverse ligament of the atlas would have sufficient strength to keep the odontoid process of the axis in its place, when deprived of its bony articulating surface, during the various movements of the head.*

* In Bérard's 'Thèse de la Luxation spontanée de l'Occipital sur l'Atlas, et de l'Atlas sur l'Axis,' a case is recorded, in which the anterior arch of the atlas suddenly gave way with a cracking sound, whilst the man to whom the accident occurred (and who died a month afterwards), was endeavouring to support a large stone upon his head. In that instance, a fungoid tumour was found in the situation of the first two cervical vertebræ, having caused absorption of the greater part of those bones, the anterior arch of the atlas having been fractured in its centre.

Note. - A case analogous to the foregoing is narrated by Mr. Keate, in the sixteenth vol. of the 'Medical Gazette' (for 1835), and the preparation illustrating this case is in the Museum of St. George's Hospital. By the kindness of Mr. Prescott Hewett, a drawing of the exfoliated portion of bone has been procured, from which the accompanying woodcut was executed.

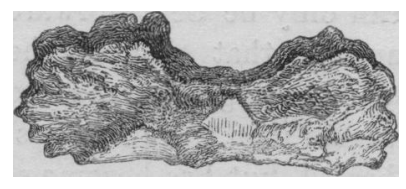

It exhibits the exfoliated fragment of the anterior arch of the atlas; including, as in Mr. Wade's patient, a portion of the articulating surface for the odontoid process of the axis. In the details of the case (locus citatus), no mention is made of this interesting part of the specimen. In addition to the above exfoliation, a large portion of the basilar surface of the occipital bone, including the lunated edge of the foramen magnum, was cast off.-ED. 